\title{
Peroxisome Proliferator-Activated Receptor $\gamma$ Ligands Isolated from Adlay Seed (Coix lacryma-jobi L. var. ma-yuen STAPF.)
}

\author{
Hiroshi Yoko,${ }^{a, b}$ Hajime Mizukami,${ }^{b}$ Akito Nagatsu, ${ }^{c}$ Takamasa Ohno, ${ }^{a}$ Hiroki Tanabe, ${ }^{a}$ and \\ Makoto INOUE ${ }^{*, a}$ \\ ${ }^{a}$ Laboratory of Medicinal Resources, School of Pharmacy, Aichi Gakuin University; 1-100 Kusumoto-cho, Chikusa-ku, \\ Nagoya 464-8650, Japan: ${ }^{b}$ Laboratory of Pharmacognosy, Graduate School of Pharmaceutical Sciences, Nagoya City \\ University; 3-1 Tanabe-dori, Mizuho-ku, Nagoya 467-8603, Japan: and ${ }^{c}$ Laboratory of Pharmacognosy, Kinjo Gakuin \\ University; 2-1723 Omori, Moriyama-ku, Nagoya 463-8521, Japan. \\ Received November 29, 2008; accepted December 25, 2008; published online January 15, 2009
}

Through screening for natural ligands against peroxisome proliferator-activated receptor $\gamma(\operatorname{PPAR} \gamma)$ using the PPAR $\gamma$ luciferase reporter assay, 6 hydroxy unsaturated fatty acids were isolated from adlay seed (Coix lacryma-jobi L. var. ma-yuen STAPF.) extracts with acetone and $70 \%$ ethanol. The structures of these compounds were determined via spectral analysis as 13-hydroxy-(9E,11E)-octadecadienoic acid (13-E,E-HODE) (1), 9-hydroxy-(10E,12E)-octadecadienoic acid (9-E,E-HODE) (2), 9-hydroxy-(10E)-octadecenoic acid (3), 10-hydroxy$(8 E)$-octadecenoic acid (4), 8-hydroxy-(9E)-octadecenoic acid (5), 11-hydroxy-(9Z)-octadecenoic acid (6). 9-E,EHODE (2) exhibited the most potent PPAR $\gamma$ agonist activity of the isolated hydroxy unsaturated fatty acids. 9$E, E$-HODE (2) and 13-E,E-HODE (1) are the respective geometrical isomers of 9-hydroxy-(10E,12Z)-octadecadienoic acid and 13-hydroxy-(9Z,11E)-octadecadienoic acid, both of which are likely to be natural PPAR $\gamma$ agonists produced in various mammalian cells, suggesting that 9-E,E-HODE may also act as PPAR $\gamma$ agonist.

Key words Adlay seed; peroxisome proliferator-activated receptor $\gamma$; fatty acid; 9-hydorxyoctadecadienoic acid; 13-hydroxyoctadecadienoic acid

Peroxisome proliferator-activated receptor $\gamma(\operatorname{PPAR} \gamma)$ is a master regulator in adipogenesis, implicated in whole-body glucose homeostasis and insulin sensitivity, and is the molecular target of thiazolidinediones, which sensitize cells to insulin and have antidiabetic effects in the liver, adipose tissue and skeletal muscle. ${ }^{1,2)}$ Recent studies have revealed that PPAR $\gamma$ is expressed in various tissues or cells involved in the control of various physiological responses including inflammation, bone homeostasis, and blood pressure. ${ }^{3,4)}$ PPAR $\gamma$ not only activates transcription of target genes for lipid metabolism, but also transrepresses expression of genes for the inflammatory response. ${ }^{5)}$ Suppression of the inflammatory response by PPAR $\gamma$ agonists is closely linked to anti-diabetic and anti-atherosclerotic effects. Thus, new insights into the pleiotropic roles of PPAR $\gamma$ on cellular functions may lead to the development of effective treatment using PPAR $\gamma$ agonists against various inflammatory disorders including diabetes, atherosclerosis, rheumatoid arthritis and bowel disease. Presently thiazolidinediones have high efficacy but a number of deleterious side effects such as peripheral edema, fluid retention and significant weight gain. ${ }^{6)}$ These adverse effects, particularly edema and fluid retention, are especially severe for patients with pre-existing cardiovascular disease due to the increased incidence of chronic heart failure from fluid accumulation and edema.7) To prevent the adverse effects of PPAR $\gamma$ full agonists, novel PPAR $\gamma$ agonists that retain beneficial clinical effects without side effects are being investigated through specific PPAR modulation in a tissue- or cellselective manner.

The adlay seed (Coix lacryma-jobi L. var. ma-yuen STAPF.), an herbal crude drug, has been widely used in Asian countries for the treatment of rheumatism, warts, neuralgia, and female endocrine disorder from ancient times. Recent studies have demonstrated that the adlay seed exhibits anti-inflammatory, anti-obesity, anti-hyperlipidemia, anti-tumor, anti- allergic, and anti-microbial effects. ${ }^{8-12)}$ Some active compounds previously isolated from the adlay seed include coixenolides that possess anti-tumor effects, ${ }^{13)}$ coixans A, B, and $\mathrm{C}$ that possess hypoglycemic effects, ${ }^{14)}$ and benzoxazinones that possess anti-inflammatory effects. ${ }^{15)}$ In our search for novel PPAR $\gamma$ agonists, we selected 88 herbal crude drugs that are frequently used in Kampo medicines. Compounds isolated from the adlay seed extract showed relatively high PPAR $\gamma$ agonist activity and the structures of the active compounds were determined to be hydroxy unsaturated fatty acids. Here, we report the activity and structure of these active compounds isolated from the adlay seed.

\section{MATERIALS AND METHODS}

General Experiment Procedures The NMR spectra were recorded in $\mathrm{CD}_{3} \mathrm{OD}$ using either a JEOL, Lambda-500 or ECA-500 spectrometer. ${ }^{1} \mathrm{H}$ - and ${ }^{13} \mathrm{C}-\mathrm{NMR}$ chemical shifts were referenced to the central peak of $\mathrm{CD}_{3} \mathrm{OD}$. Electron impact mass spectra (EI-MS) were measured with a JEOL Sx102 spectrometer. Silica gel BW-200 (Fuji Silysia Chemicals Co., Ltd.) was used for column chromatography. Chromatographic fractions were monitored by TLC using pre-coated plates (Kieselgel 60 F254, $0.25 \mathrm{~mm}$ thick, Merck no. 5715) and then detected by UV light at $254 \mathrm{~nm}$ and by color reaction following heating the plates after spraying with a solution of vanillin in sulfuric acid/ethanol. Adlay seed and other crude drugs were purchased from Tsumura \& Co. (Tokyo, Japan). HEK293 and 3T3-L1 cells were obtained from the RIKEN Cell Bank (Tsukuba, Japan) and JCRB Cell Bank (Osaka, Japan), respectively.

Extraction and Isolation Dry adlay seeds $(2.0 \mathrm{~kg})$ were extracted with $100 \%$ acetone $(141 \times 3$ times) at room temperature for $24 \mathrm{~h}$. The extracts were filtered, combined and concentrated in vacuo. The residue (103 g) was suspended in 
$80 \% \mathrm{MeOH}$ and partitioned with $n$-hexane to obtain $n$ hexane-soluble material $(98.7 \mathrm{~g})$. The $80 \% \mathrm{MeOH}$ soluble material was then suspended in $\mathrm{H}_{2} \mathrm{O}$ and further partitioned with AcOEt to obtain AcOEt-soluble (2.15 g) and $\mathrm{H}_{2} \mathrm{O}$-soluble $(2.62 \mathrm{~g})$ material. Among these 3 fractions, the AcOEt soluble material showed the highest $\operatorname{PPAR} \gamma$ transcriptional activity. Therefore, the AcOEt fraction was subjected to silica gel column chromatography ( $n$-hexane : AcOEt $=3: 2)$ to obtain 7 fractions. The most potent fraction was further separated on silica gel column chromatography (chloroform : AcOEt=9:1) into 3 fractions. The active fraction was subjected to preparative reverse-phase high-performance liquid chromatography (HPLC) (YMC J'shere ODS-H80, $10 \mathrm{~mm} \times 250 \mathrm{~mm} ; 70 \%$ acetonitrile) to yield the following hydroxy unsaturated fatty acids: 1 (5.4 mg), 2 (3.1 mg), 3 (1.9 $\mathrm{mg})$ and 4 (3.0 $\mathrm{mg})$.

Using the same method as the acetone extraction, the adlay seeds were extracted with $70 \% \mathrm{EtOH}$ to isolate hydroxy unsaturated fatty acids. Dry adlay seeds $(1 \mathrm{~kg})$ were extracted three times with $70 \% \mathrm{EtOH}(101)$ and combined to obtain the total extract $(32 \mathrm{~g})$. Following fractionation, AcOEt-soluble material ( $1.7 \mathrm{~g})$ was separated by column chromatography and HPLC using assay-guided fractionation to yield the following hydroxy unsaturated fatty acids as active compounds: 5 (3.8 mg) and $\mathbf{6}(11.9 \mathrm{mg})$; compounds $\mathbf{5}$ and $\mathbf{6}$ together with $\mathbf{1 - 4}$ made up the active compounds of the adlay seeds.

Identification of Hydroxy Unsaturated Fatty Acids by EI-MS and ${ }^{\mathbf{1}}$ H-NMR 13-Hydroxy-(9E,11E)-octadecadienoic Acid (13-E,E-HODE) 1: EI-MS m/z: $278\left(\mathrm{M}^{+}-\mathrm{H}_{2} \mathrm{O}\right.$, 100); ${ }^{1} \mathrm{H}-\mathrm{NMR}\left(\mathrm{CD}_{3} \mathrm{OD}, 500 \mathrm{MHz}\right) \delta: 0.89(3 \mathrm{H}, \mathrm{t}, J=6.5 \mathrm{~Hz}$, $\left.18-\mathrm{H}_{3}\right), 1.31-1.50\left(2 \mathrm{H}, \mathrm{m}, 4-7,14-17-\mathrm{H}_{2}\right), 1.58(2 \mathrm{H}, \mathrm{m}$, $\left.3-\mathrm{H}_{2}\right), 2.07(2 \mathrm{H}, \mathrm{dt}, J=6.9,6.9 \mathrm{~Hz}, 8-\mathrm{H}), 2.26\left(2 \mathrm{H}, \mathrm{m}, 2-\mathrm{H}_{2}\right)$, $4.00(1 \mathrm{H}, \mathrm{dt}, J=6.9,6.3 \mathrm{~Hz}, 13-\mathrm{H}), 5.50(1 \mathrm{H}, \mathrm{dd}, J=15.1$, $6.9 \mathrm{~Hz}, 12-\mathrm{H}), 5.66(1 \mathrm{H}, \mathrm{dt}, J=14.9,6.9 \mathrm{~Hz}, 9-\mathrm{H}), 6.01(1 \mathrm{H}$, dd, $J=15.1,10.5 \mathrm{~Hz}, 10-\mathrm{H}), 6.12(1 \mathrm{H}, \mathrm{dd}, J=14.9,10.5 \mathrm{~Hz}$, 11-H).

9-Hydroxy-(10E,12E)-octadecadienoic Acid (9-E,EHODE) 2: EI-MS $m / z$ : $278\left(\mathrm{M}^{+}-\mathrm{H}_{2} \mathrm{O}, 99\right) ;{ }^{1} \mathrm{H}-\mathrm{NMR}$ $\left(\mathrm{CD}_{3} \mathrm{OD}, 500 \mathrm{MHz}\right) \delta: 0.89\left(3 \mathrm{H}, \mathrm{t}, J=6.5 \mathrm{~Hz}, 18-\mathrm{H}_{3}\right), 1.31-$ $1.50\left(2 \mathrm{H}, \mathrm{m}, 4-7,14-17-\mathrm{H}_{2}\right), 1.58\left(2 \mathrm{H}, \mathrm{m}, 3-\mathrm{H}_{2}\right), 2.06$ $(2 \mathrm{H}, \mathrm{dt}, J=7.2,6.9 \mathrm{~Hz}, 14-\mathrm{H}), 2.26\left(2 \mathrm{H}, \mathrm{m}, 2-\mathrm{H}_{2}\right), 4.00(1 \mathrm{H}$, $\mathrm{dt}, J=6.8,6.3 \mathrm{~Hz}, 9-\mathrm{H}), 5.50(1 \mathrm{H}, \mathrm{dd}, J=14.9,6.9 \mathrm{~Hz}, 10-\mathrm{H})$, $5.66(1 \mathrm{H}, \mathrm{dt}, J=15.2,6.8 \mathrm{~Hz}, 13-\mathrm{H}), 6.01(1 \mathrm{H}, \mathrm{dd}, J=14.9$, $10.3 \mathrm{~Hz}, 12-\mathrm{H}), 6.12$ (1H, dd, $J=15.2,10.3 \mathrm{~Hz}, 11-\mathrm{H})$.

9-Hydroxy-(10E)-octadecenoic Acid 3: EI-MS m/z: 280 $\left(\mathrm{M}^{+}-\mathrm{H}_{2} \mathrm{O}, 54\right) ;{ }^{1} \mathrm{H}-\mathrm{NMR}\left(\mathrm{CD}_{3} \mathrm{OD}, 500 \mathrm{MHz}\right) \delta: 0.89(3 \mathrm{H}, \mathrm{t}$, $\left.J=7.0 \mathrm{~Hz}, 18-\mathrm{H}_{3}\right), 1.29-1.50\left(2 \mathrm{H}, \mathrm{m}, 4-8,13-17-\mathrm{H}_{2}\right)$, $1.59\left(2 \mathrm{H}, \mathrm{m}, 3-\mathrm{H}_{2}\right), 2.03\left(2 \mathrm{H}, \mathrm{m}, 12-\mathrm{H}_{2}\right), 2.23\left(2 \mathrm{H}, \mathrm{m}, 2-\mathrm{H}_{2}\right)$, $3.94(1 \mathrm{H}, \mathrm{dt}, J=6.5,7.0 \mathrm{~Hz}, 9-\mathrm{H}), 5.39(1 \mathrm{H}, \mathrm{dd}, J=15.8$, $7.0 \mathrm{~Hz}, 10-\mathrm{H}), 5.59$ (1H, dt, $J=15.8,7.0 \mathrm{~Hz}, 11-\mathrm{H})$.

10-Hydroxy-( $8 E)$-octadecenoic Acid 4: EI-MS $\mathrm{m} / \mathrm{z}: 280$ $\left(\mathrm{M}^{+}-\mathrm{H}_{2} \mathrm{O}, 27 ;{ }^{1} \mathrm{H}-\mathrm{NMR}\left(\mathrm{CD}_{3} \mathrm{OD}, 500 \mathrm{MHz}\right) \delta: 0.86(3 \mathrm{H}, \mathrm{t}\right.$, $\left.J=7.0 \mathrm{~Hz}, 18-\mathrm{H}_{3}\right), 1.25-1.51\left(2 \mathrm{H}, \mathrm{m}, 4-6,11-17-\mathrm{H}_{2}\right)$, $1.61\left(2 \mathrm{H}, \mathrm{m}, 3-\mathrm{H}_{2}\right), 2.00\left(2 \mathrm{H}, \mathrm{m}, 7-\mathrm{H}_{2}\right), 2.33\left(2 \mathrm{H}, \mathrm{m}, 2-\mathrm{H}_{2}\right)$, $4.00(1 \mathrm{H}, \mathrm{m}, 10-\mathrm{H}), 5.42$ (1H, dd, $J=15.5,6.8 \mathrm{~Hz}, 9-\mathrm{H}), 5.59$ $(1 \mathrm{H}, \mathrm{dt}, J=15.5,6.8 \mathrm{~Hz}, 8-\mathrm{H})$.

8-Hydroxy-(9E)-octadecenoic Acid 5: EI-MS $m / z: 280$ $\left(\mathrm{M}^{+}-\mathrm{H}_{2} \mathrm{O}, 25\right) ;{ }^{1} \mathrm{H}-\mathrm{NMR}\left(\mathrm{CD}_{3} \mathrm{OD}, 500 \mathrm{MHz}\right) \delta: 0.88(3 \mathrm{H}, \mathrm{t}$, $\left.J=7.0 \mathrm{~Hz}, 18-\mathrm{H}_{3}\right), 1.28-1.49\left(2 \mathrm{H}, \mathrm{m}, 4-7,12-17-\mathrm{H}_{2}\right)$, $1.58\left(2 \mathrm{H}, \mathrm{m}, 3-\mathrm{H}_{2}\right), 2.02\left(2 \mathrm{H}, \mathrm{m}, 11-\mathrm{H}_{2}\right), 2.26\left(2 \mathrm{H}, \mathrm{m}, 2-\mathrm{H}_{2}\right)$,
$3.93(1 \mathrm{H}, \mathrm{dt}, J=7.0,6.5 \mathrm{~Hz}, 8-\mathrm{H}), 5.38(1 \mathrm{H}, \mathrm{dd}, J=15.2$, $7.4 \mathrm{~Hz}, 9-\mathrm{H}), 5.58(1 \mathrm{H}, \mathrm{dt}, J=15.2,6.9 \mathrm{~Hz}, 10-\mathrm{H})$.

11-Hydroxy-(9Z)-octadecenoic Acid 6: EI-MS m/z: 280 $\left(\mathrm{M}^{+}-\mathrm{H}_{2} \mathrm{O}, 14\right) ;{ }^{1} \mathrm{H}-\mathrm{NMR}\left(\mathrm{CD}_{3} \mathrm{OD}, 500 \mathrm{MHz}\right) \delta: 0.88(3 \mathrm{H}, \mathrm{t}$, $\left.J=7.0 \mathrm{~Hz}, 18-\mathrm{H}_{3}\right), 1.29-1.37\left(2 \mathrm{H}, \mathrm{m}, 4-7,13-17-\mathrm{H}_{2}\right)$, $1.57\left(2 \mathrm{H}, \mathrm{m}, 3-12-\mathrm{H}_{2}\right), 2.07\left(2 \mathrm{H}, \mathrm{m}, 8-\mathrm{H}_{2}\right), 2.25(2 \mathrm{H}, \mathrm{t}$, $\left.J=7.5 \mathrm{~Hz}, 2-\mathrm{H}_{2}\right), 4.35(1 \mathrm{H}, \mathrm{m}, 11-\mathrm{H}), 5.30(1 \mathrm{H}, \mathrm{dd}, J=11.0$, $9.0 \mathrm{~Hz}, 10-\mathrm{H}), 5.43(1 \mathrm{H}, \mathrm{dt}, J=11.0,7.5 \mathrm{~Hz}, 9-\mathrm{H})$.

Determination of the Hydroxy Group Positions of 1 to 6 Hydroxy unsaturated fatty acids $\mathbf{1}$ to $\mathbf{6}$ were treated with trimethylchlorosilane and hexamethyldisilazane (TMS-HT, Tokyo Kasei) at room temperature. The reaction mixtures were subjected to EI-MS measurement to detect the following peaks. TMS ether of 1: $368\left(\mathrm{M}^{+}, 11\right)$ and 297 $\left(\left[\mathrm{M}^{+}-\mathrm{C}_{5} \mathrm{H}_{11}\right]^{+}, 28\right)$. TMS ether of 2: $368\left(\mathrm{M}^{+}, 19\right)$ and 225 $\left(\left[\mathrm{M}^{+}-\mathrm{C}_{8} \mathrm{H}_{15} \mathrm{O}_{2}\right]^{+}, 100\right)$. TMS ether of 3: $370\left(\mathrm{M}^{-}, 1\right)$ and $227\left(\left[\mathrm{M}^{+}-\mathrm{C}_{8} \mathrm{H}_{15} \mathrm{O}_{2}\right]^{+}, 100\right)$. TMS ether of 4: $370\left(\mathrm{M}^{+}, 2\right)$ and $257\left(\left[\mathrm{M}^{+}-\mathrm{C}_{8} \mathrm{H}_{17}\right]^{+}, 100\right)$. TMS ether of 5: $370\left(\mathrm{M}^{+}, 1\right)$ and $241\left(\left[\mathrm{M}^{+}-\mathrm{C}_{7} \mathrm{H}_{13} \mathrm{O}_{2}\right]^{+}, 100\right)$. TMS-ether of $\mathbf{6 :} 370\left(\mathrm{M}^{+}\right.$, 1) and $271\left(\left[\mathrm{M}^{+}-\mathrm{C}_{7} \mathrm{H}_{15}\right]^{+}, 100\right)$.

Luciferase Reporter Assay PPAR $\gamma$ agonist activity was determined by luciferase reporter assay as follows. HEK293 cells $\left(1.5 \times 10^{5}\right.$ cells/well $)$ were seeded in 24 -well culture plates and maintained in minimal essential medium (MEM) containing $10 \%$ fetal bovine serum (FBS) and $10 \mathrm{ml} / 1$ of nonessential amino acid at $37^{\circ} \mathrm{C}$ under $5 \% \mathrm{CO}_{2}$ in air. The cells were transfected by a standard calcium-phosphate precipitation method with $100 \mathrm{ng}$ pCMX-PPAR $\gamma 1$ expression vector, $100 \mathrm{ng}$ pPPREx3-TK-luc reporter plasmid and $10 \mathrm{ng}$ pCMX$\beta$-gal expression vector. After incubating for $20 \mathrm{~h}$, the cells were thoroughly washed with fresh medium and continued to incubate in the presence of the compounds at the concentrations indicated in the figure legends. After incubating for an additional $20 \mathrm{~h}$, the cells were harvested to determine the luciferase and $\beta$-galactosidase. Luciferase activity was normalized relative to the activity of an internal $\beta$-galactosidase control and expressed as the relative luciferase activity. The luciferase activity was determined in triplicate experiments.

Binding Activity of PPAR $\boldsymbol{\gamma}$ Agonist A binding assay was performed using $\mathrm{Nu}$ ligand kit (Microsystems, Kyoto, Japan) according to the manufacturer's instructions. Briefly, $100 \mu \mathrm{l}$ glutation $S$-transferase-fused nuclear receptor protein dissolved in $0.1 \mathrm{M}$ sodium carbonate buffer $(\mathrm{pH}$ 6.8) was added to a 96-well plate and incubated overnight at $4{ }^{\circ} \mathrm{C}$. After washing the plate thoroughly with $120 \mu \mathrm{l}$ washing buffer A, alkaline phosphatase-fused transcription intermediary factor 2 (TIF2) protein and test compounds dissolved in dimethylsulfoxide (DMSO) were added and the plate was incubated for $1 \mathrm{~h}$ at $4^{\circ} \mathrm{C}$. The plate was then washed with $120 \mu \mathrm{l}$ buffer $\mathrm{B}$. The enzyme reaction at $30^{\circ} \mathrm{C}$ was started by the addition of $100 \mu \mathrm{l} p$-nitrophenylphosphoric acid solution. When the solution turned yellow, the reaction was stopped by the addition of $25 \mu \mathrm{l} 0.5 \mathrm{M} \mathrm{NaOH}$. The absorbance at $405 \mathrm{~nm}$ was measured with a multilabel counter (ARVOTM 1420; Wallac, Finland).

Adipocyte Differentiation in 3T3-L1 Preadipocyte Cells Mouse 3T3-L1 preadipocyte cells were maintained in Dulbecco's modified essential medium (DMEM) containing 10\% calf serum (CS), $100 \mathrm{U} / \mathrm{ml}$ penicillin, and $100 \mu \mathrm{g} / \mathrm{ml}$ streptomycin (Sigma, CA, U.S.A.). For differentiation, $2 \mathrm{~d}$ after the cells were grown to confluency, the medium was replaced 
with DMEM supplemented with $10 \% \mathrm{CS}, 1 \mu \mathrm{g} / \mathrm{ml}$ insulin, $0.25 \mu \mathrm{M}$ dexamethasone, $0.5 \mathrm{~mm}$ 3-isobutyl-1-methylxanthine (IBMX), $100 \mathrm{U} / \mathrm{ml}$ penicillin, and $100 \mu \mathrm{g} / \mathrm{ml}$ streptomycin and cultured for $2 \mathrm{~d}$. Then, the medium was replaced with DMEM supplemented with $10 \% \mathrm{CS}, 0.5 \mu \mathrm{g} / \mathrm{ml}$ insulin, $100 \mathrm{U} / \mathrm{ml}$ penicillin, and $100 \mu \mathrm{g} / \mathrm{ml}$ streptomycin and cultured for an additional $2 \mathrm{~d}$. Finally, the cells were maintained in DMEM containing $10 \% \mathrm{CS}, 100 \mathrm{U} / \mathrm{ml}$ penicillin, and $100 \mu \mathrm{g} / \mathrm{ml}$ streptomycin, while the medium was replaced with fresh media every 2 days. On day 8, the cells were washed twice with cold phosphate-buffered saline (PBS), fixed in $10 \%$ formaldehyde in PBS for $1 \mathrm{~h}$ and then stained with $0.3 \%(\mathrm{w} / \mathrm{v})$ Oil red $\mathrm{O}$ solution (60\% isopropanol, $40 \%$ water) for $1 \mathrm{~h}$ at room temperature. After staining, the cells were washed three times with water and then photographed.

Statistical Analysis Data were expressed as the means \pm S.D. Data were evaluated for statistical significance by one-way ANOVA, followed by Bonferroni's $t$-test or by Student's $t$-test. A value of $p<0.05$ was considered to be statistically significant.

\section{RESULTS}

A total of 88 herbal crude drugs frequently used in Kampo medicines were selected and screened for PPAR $\gamma$ agonist activity by the PPAR $\gamma$ luciferase reporter assay. The adlay seed showed a higher PPAR $\gamma$ transcriptional activity than the other herbal crude drugs (PPAR $\gamma$ agonist troglitazone (5 $\mu \mathrm{M}): 3.36 \pm 0.40$, adlay seed: $1.95 \pm 0.15$, artemisia capillaris flower: $1.78 \pm 0.34$, chrysanthemum flower: $1.70 \pm 0.12$, trichosanthes seed: $1.54 \pm 0.11$, anemarrhena rhizoma: $1.47 \pm$ 0.15 , glycyrrhiza: $1.42 \pm 0.23$, schizonepeta spike: $1.41 \pm 0.19$ (crude drug extracts were used at the concentration of $50 \mu \mathrm{g} / \mathrm{ml})$ ). To isolate the active compounds, both the acetone and $70 \%$ EtOH extracts of adlay seeds were fractionated following the PPAR $\gamma$ reporter assay using various methods of chromatography to yield the final hydroxy unsaturated fatty acids $\mathbf{1}-\mathbf{4}$ from acetone extraction and $\mathbf{5}$ and $\mathbf{6}$ from $70 \%$ EtOH extraction (Fig. 1).

The EI-MS results of $\mathbf{1}$ showed a dehydrated fragment ion peak at $m / z 278$. The UV $\left(\lambda_{\max }: 235 \mathrm{~nm}\right)$ and ${ }^{1} \mathrm{H}-\mathrm{NMR}$ spectra indicated that 1 possesses conjugated olefins. The $J$ values $(14.9,15.1 \mathrm{~Hz})$ of olefin protons and the COSY spectrum also indicated that $\mathbf{1}$ possesses a conjugated $E, E$-diene with a hydroxy group at the allyl position in the straight carbon chain. To determine the position of the hydroxy group and the olefins, trimethylsilylation of $\mathbf{1}$ was performed, followed by EI-MS measurement. As the EI-MS results showed the fragment ion peak at $297\left(\left[\mathrm{M}-\mathrm{C}_{5} \mathrm{H}_{11}\right]^{+}\right.$, Fig. 2), the position of the hydroxy group was determined to be at C-13. Therefore, the structure of $\mathbf{1}$ was determined to be 13-hydroxy$(9 E, 11 E)$-octadecadienoic acid (13-E,E-HODE).

Compound 2 showed very similar spectral data to $13-E, E-$ $\operatorname{HODE}(\mathbf{1})$, suggesting it also was a hydroxy- $(E, E)$-octadecadienoic acid. The EI-MS results of TMS ether showed a fragment ion peak at $225\left(\left[\mathrm{M}-\mathrm{C}_{8} \mathrm{H}_{15} \mathrm{O}_{2}\right]^{+}\right)$, indicating the position of the hydroxy group of 2 was at C-9. The positions of the hydroxy group and olefins of $\mathbf{2}$ were also supported by the correlation between terminal methyl $(\delta 0.89)$ and $14-\mathrm{H}_{2}$ $(\delta$ 2.06) in the HOHAHA spectrum (Fig. 1). Thus, the structure of 2 was determined to be 9-hydroxy-(10E,12E)-octa-

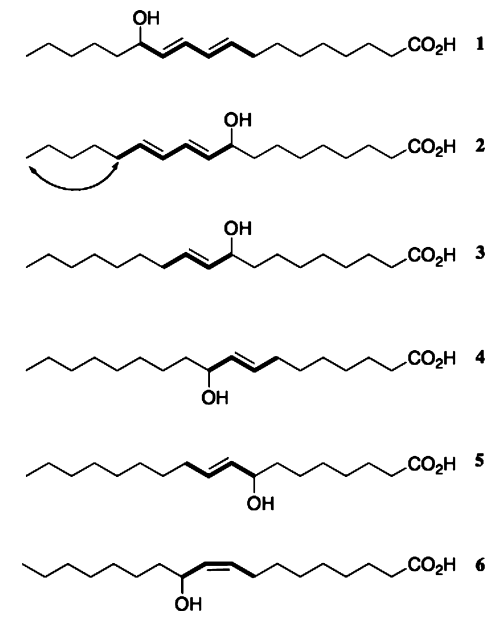

Fig. 1. Structures of Hydroxy Unsaturated Fatty Acids (1-6)

The selected COSY correlations were indicated as bold lines and the selected HOHAHA correlation was indicated as an arrow.
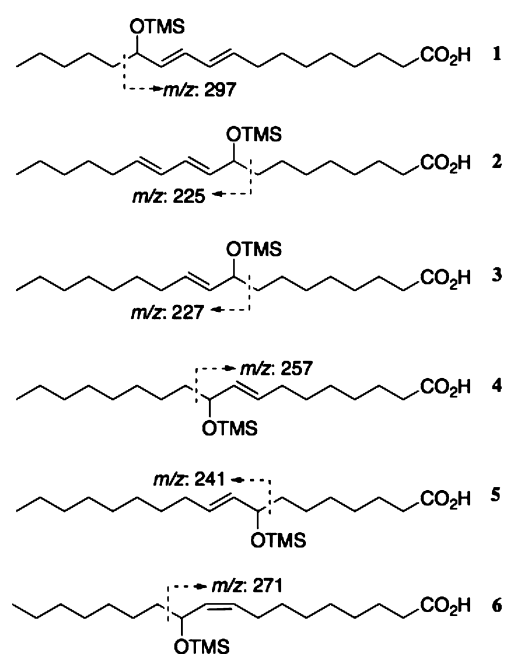

Fig. 2. Detected Fragments in EI-MS Spectra of TMS Ethers of $\mathbf{1}-\mathbf{6}$

decadienoic acid (9-E,E-HODE).

The EI-MS results of 3 showed a dehydrated peak at $\mathrm{m} / \mathrm{z}$ 280, which was 2 mass units larger than that of $13-E, E$ HODE (1). The ${ }^{1} \mathrm{H}-\mathrm{NMR}$ results of $\mathbf{3}$ showed similar spectral data to $13-E, E$-HODE (1), except for that corresponding to one $E$ olefin. The EI-MS results of $\mathbf{3}$ showed a fragment ion peak for TMS ether at $m / z 227\left(\left[\mathrm{M}-\mathrm{C}_{8} \mathrm{H}_{15} \mathrm{O}_{2}\right]^{+}\right.$, Fig. 2). Taken together, the structure of 3 was determined to be 9-hydroxy-(10E)-octadecenoic acid.

The spectral data of $\mathbf{4}$ and $\mathbf{5}$ were very similar to those of $\mathbf{3}$, indicating that they are isomers of $\mathbf{3}$. As the EI-MS results of $\mathbf{4}$ and $\mathbf{5}$ showed the fragment ion peaks for TMS ethers at $257\left(\left[\mathrm{M}-\mathrm{C}_{8} \mathrm{H}_{17}\right]^{+}\right)$and $241\left(\left[\mathrm{M}-\mathrm{C}_{7} \mathrm{H}_{13} \mathrm{O}_{2}\right]^{+}\right.$, Fig. 2), respectively, the structure of $\mathbf{4}$ was determined to be 10-hydroxy-( $8 E)$-octadecenoic acid and 5 to be 8-hydroxy-(9E)octadecenoic acid.

Compound $\mathbf{6}$ also had similar spectral data to those of $\mathbf{3}$, except for those corresponding to the olefins. As the $J$ values of olefin protons were $11.0 \mathrm{~Hz}$ and the EI-MS results of 6 showed the fragment ion peak for TMS ether at 271 $\left(\left[\mathrm{M}-\mathrm{C}_{7} \mathrm{H}_{15}\right]^{+}\right.$, Fig. 2), the structure of $\mathbf{6}$ was determined to be 11-hydroxy-(9Z)-octadecenoic acid. As the optical rota- 


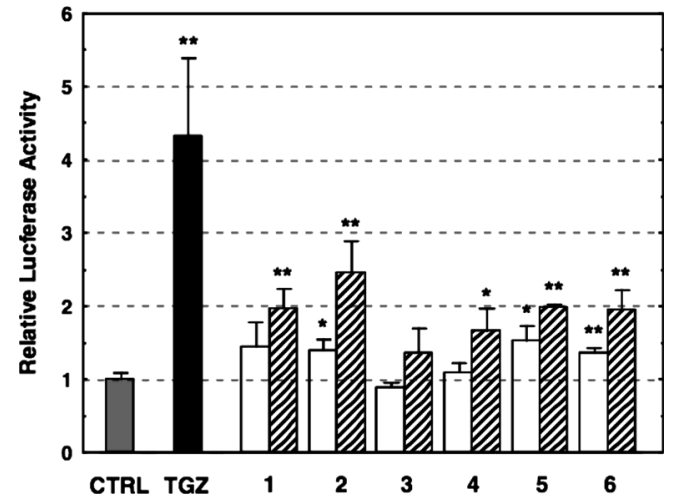

Fig. 3. Effects of Hydroxy Unsaturated Fatty Acids Isolated from Adlay Seeds on Activation of PPAR $\gamma$ in Luciferase Reporter Assay

pPPREx3-TK-luc and pCMX- $\beta$ gal were transfected into HEK293 cells together with pCMX-PPAR $\gamma 1.20 \mathrm{~h}$ after the transfection, the cells were treated with various hydroxy unsaturated fatty acid $1-6$ at the concentration of $2 \mu \mathrm{M}$ (open column) or $20 \mu \mathrm{M}$ (hatched column) for $20 \mathrm{~h}$. The activity of vehicle control set at 1 , and relative luciferase activity was presented as fold induction relative to that of the vehicle control Troglitazone (TGZ) $(5 \mu \mathrm{M})$ was used as a PPAR $\gamma$ agonist. The values are represented as means \pm S.D. of three determinants from a representative of three independent experiments, which showed similar results. $* p<0.05, * * p<0.01 v s$. vehicle control (Student's $t$-test).

tions of $\mathbf{1}-\mathbf{6}$ were 0 , all these compounds were racemic.

Examination of the PPAR $\gamma$ agonist activities of these hydroxy unsaturated fatty acids $\mathbf{1}-\mathbf{6}$ revealed that 9-E,EHODE (2) exhibited the most potent activity of all the hydroxy unsaturated fatty acids isolated from adlay seeds, although at a much lower activity level than that of the PPAR $\gamma$ full agonist troglitazone (Fig. 3). 9-E,Z-HODE (9-HODE) and $13-Z, E-H O D E$ (13-HODE), which are geometrical isomers of 9-E,E-HODE (2) and 13-E,E-HODE (1), respectively, are reported to be physiologically relevant endogenous PPAR $\gamma$ agonists in mammals. ${ }^{16)}$ Polyunsaturated fatty acids are also known to be endogenous PPAR $\gamma$ agonists. ${ }^{17)}$ As in similar reports, ${ }^{18)}$ 9-HODE showed the most potent activity, followed by 13-HODE, eicosapentaenoic acid and linoleic acid (Fig. 4A). On the other hand, 9-E,E-HODE (2) showed a PPAR $\gamma$ agonist activity as potent as 9-HODE and much more potent than eicosapentaenoic acid and linoleic acid (Fig. 4A), and 13-E,E-HODE (1) was a less potent PPAR $\gamma$ agonist than 13-HODE but comparable to eicosapentaenoic acid and linoleic acid.

Investigation of the binding activity of $9-E, E-H O D E(2)$ and $13-E, E$-HODE (1) to PPAR $\gamma$ by determining agonist-dependent interaction of PPAR $\gamma$ with a coactivator TIF2 using the CoA-BAP assay system revealed that both $9-E, E-\mathrm{HODE}$ (2) and 13-E,E-HODE (1) bound directly to PPAR $\gamma$ to the same degree that troglitazone did (Fig. 4B). To study the PPAR $\gamma$ agonist activity of 9-E,E-HODE (2) in cells, the effect on differentiation of 3T3-L1 preadipocyte cells to adipocytes was also examined. As shown in Fig. 5, 9-E,EHODE (2) was confirmed to induce 3T3-L1 preadipocyte cell differentiation in a similar manner to the PPAR $\gamma$ full agonist rosiglitazone and 9-HODE; a similar effect was also observed in the adlay seed extract. Finally, as 9-HODE and 13-HODE are reported to activate $\operatorname{PPAR} \alpha{ }^{19}{ }^{19}$ we studied whether 9-E,E-HODE (2) and 13-E,E-HODE (1) are able to activate $\operatorname{PPAR} \alpha$ in $\operatorname{PPAR} \alpha$ luciferase reporter assay. Although data are not shown, the results indicate that both 9$E, E$-HODE (2) and 13-E,E-HODE (1) activate PPAR $\alpha$-de-
(A)

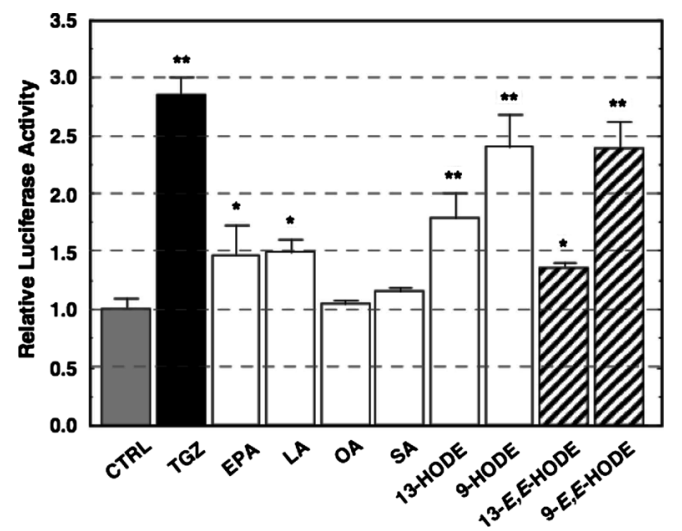

(B)

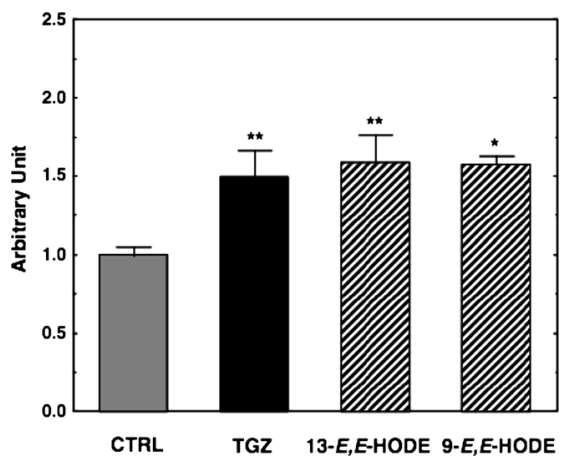

Fig. 4. Relative Activation of PPAR $\gamma$ and Binding Activity to PPAR $\gamma$ by 9-E,E-HODE (2)

(A) pPPREx3-TK-luc and pCMX- $\beta$ gal were transfected into HEK293 cells together with pCMX-PPAR $\gamma 1.20 \mathrm{~h}$ after the transfection, the cells were treated with EPA; eicosapentaenoic acid, LA; linoleic acid, OA; oleic acid, SA; stearic acid, 13-HODE, 9HODE, 13-E,E-HODE (1) and 9-E,E-HODE (2) at the concentration of $40 \mu \mathrm{M}$ for $20 \mathrm{~h}$. Troglitazone (TGZ) was used at $5 \mu \mathrm{M}$. The values are represented as means \pm S.D. of three determinants from a representative of three independent experiments, which showed similar results. $* p<0.05, * * p<0.01 v s$. vehicle control (ANOVA and Bonferroni-type multiple $t$-test). (B) Ligand-dependent interactions between GST-PPAR $\gamma$ and TIF2-BAP were determined according to the method described in Materials and Methods. 13-E,E-HODE (1), 9-E,E-HODE (2), and TGZ were used at 20,20 , and $10 \mu \mathrm{M}$, respectively. The values are represented as means \pm S.D. of three determinants from a representative of three independent experiments, which showed similar results. $* p<0.05$, $* * p<0.01 v s$. vehicle control (Student's $t$-test).

pendent transcription in a similar manner to 9-HODE and 13-HODE.

\section{DISCUSSION}

In the present study, 88 herbal crude drugs were screened for PPAR $\gamma$ agonists and 6 hydroxy unsaturated fatty acids were isolated for the first time from the seed of Coix lacryma-jobi L. var. ma-yuen STAPF. Among them, the most potent $\operatorname{PPAR} \gamma$ agonist was 9-E,E-HODE (2), which is a geometrical isomer of 9-HODE. Furthermore, 13-E,E-HODE (1), which is a geometrical isomer of 13-HODE, was also isolated as a weak PPAR $\gamma$ agonist. Hydroxy unsaturated fatty acids occur in various organism species, and 13-E,E-HODE (1) ${ }^{20)} 9-E, E-H O D E(2),{ }^{21)}$ and other hydroxy unsaturated fatty acids $^{22)}$ have already been isolated from plants and fungi, although there are few studies on their biological activity. Both 9-HODE and 13-HODE are produced by cyclooxygenase and/or lipoxygenase in mammalian cells such as endothelial, epithelial, and smooth muscle cells, as well as blood cells including neutrophils, basophils, monocytes, and lymphocytes. ${ }^{23-26)}$ It has been reported that PPAR $\gamma$ is acti- 


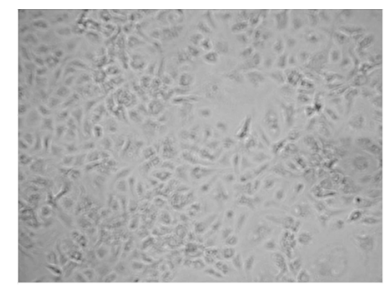

Non-differentiation

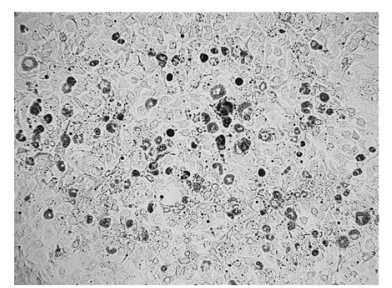

Adlay seed extract

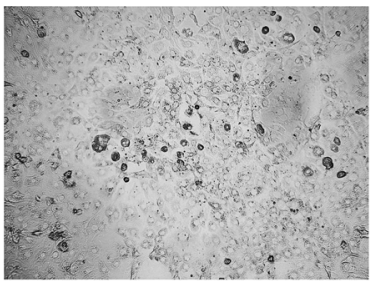

CTRL

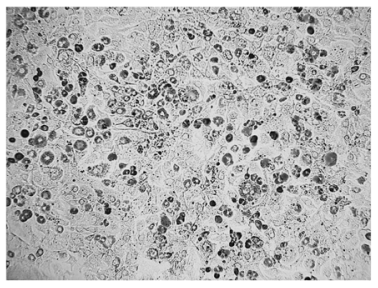

9-E,E-HODE

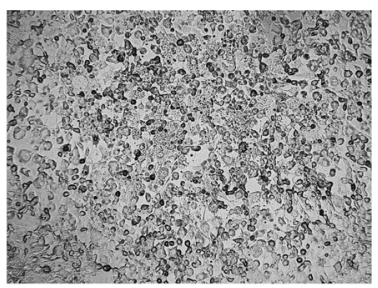

Rosiglitazone

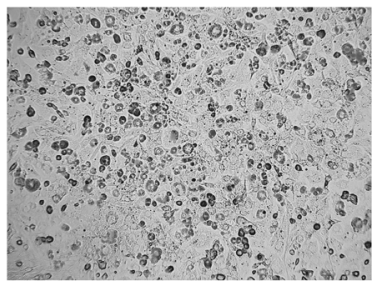

9-HODE

Fig. 5. Effect of 9-E,E-HODE (2) on the Differentiation of 3T3-L1 Preadipocyte Cells

Post-confluent mouse 3T3-L1 preadipocyte cells were cultured in DMEM medium containing $1 \mu \mathrm{g} / \mathrm{ml}$ insulin, $0.25 \mu \mathrm{M}$ dexamethazone, and $0.5 \mathrm{~mm}$ IBMX for $2 \mathrm{~d}$, followed by $0.5 \mu / \mathrm{ml}$ insulin for 2 day. After $4 \mathrm{~d}$ culture in the differentiation-inducing medium, the cells were maintained in DMEM medium without hormones for $4 \mathrm{~d}$. Adlay seed extract $(100 \mu \mathrm{g} / \mathrm{ml}), 9-E, E-H O D E(2)(20 \mu \mathrm{M}), 9-\operatorname{HODE}(20 \mu \mathrm{M})$, and rosiglitazone $(5 \mu \mathrm{M})$ were added to the cultures throughout the experiment. Cells were fixed and stained with Oil-red $\mathrm{O}$ on the day 8 .

vated by 15 -deoxy- $\Delta^{12,14}-\mathrm{PGJ}_{2}, 9-\mathrm{HODE}, 13-\mathrm{HODE}, 5-, 12-$, and 15-hydroxyeicosatetraenoic acids (15-HETE) as endogenous agonists, although the physiological relevance of the agonists has not been determined. ${ }^{27)}$ However, Itoh et al. recently reported that PPAR $\gamma$ can accommodate two 9-HODE molecules simultaneously or one 13-HODE molecule at a different position in the large ligand-binding pocket of PPAR $\gamma{ }^{16)}$ These results strongly suggest that 9-HODE and 13-HODE, in addition to oxo fatty acids, are physiologically relevant PPAR $\gamma$ agonists. In our study, 9-E,E-HODE (2) was found to activate PPAR $\gamma$-dependent transcriptional activity as efficiently as 9-HODE in the PPAR $\gamma$ luciferase reporter assay and it induced the differentiation of 3T3-L1 preadipocyte cells to adipocytes, whereas $13-E, E-H O D E ~(1)$ showed less potent PPAR $\gamma$ agonist activity than 13-HODE. $\operatorname{PPAR} \gamma$ has a large Y-shape ligand-binding pocket with a volume of around $1400 \AA^{3}$ and can accommodate one or a couple of various lipophilic ligands. According to Itoh et al., the binding of two 9-HODE molecules or one 13-HODE molecule stabilizes the conformation of PPAR $\gamma$, resulting in transmitting signals, suggesting that 9-E,E-HODE (2) may also be accommodated to the same position in the ligand-binding pocket, regardless of the conformational difference of 9-E,EHODE (2) with two trans double bonds. On the other hand, the difference in the structure of 13-E,E-HODE (1) and 13HODE may affect the entry and/or binding of $13-E, E-H O D E$ (1) to the PPAR $\gamma$-binding pocket, or the 13-E,E-HODE (1)induced PPAR $\gamma$ conformational change may fail to recruit coactivators or release corepressors, resulting in a significant reduction in the activation of PPAR $\gamma$-dependent gene transcription. Therefore, assuming a difference exists in the binding ability between 9-E,E-HODE (2) and 9-HODE, 9-E,EHODE (2) may induce a subtle conformational change in $\operatorname{PPAR} \gamma$, resulting in the recruitment of different coactivators and the activation of a set of genes distinct from 9-HODE. This notion is supported by the fact that 13-HODE and 15HETE, as well as rosiglitazone, preferentially induce the in- teraction of PPAR $\gamma /$ retinoid X receptor (RXR) heterodimers with a coactivator cyclic AMP response element binding protein (CREB)-binding protein, whereas 15 -deoxy- $\Delta^{12,14}-\mathrm{PGJ}_{2}$ induces the interaction with steroid receptor coactivator- $1 .^{28)}$ Taken together, our major findings show that 9-E,E-HODE (2) is as potent a PPAR $\gamma$ agonist as 9-HODE, despite being a geometrical isomer, and is more potent than other polyunsaturated fatty acids; and demonstrate that the adlay seed is rich in exogenous PPAR $\gamma$ agonists similar to physiologically relevant endogenous PPAR $\gamma$ agonists.

Although there are few studies concerning PPAR $\gamma$ dependent effects of 9-HODE and 13-HODE, a recent study has demonstrated that 13-HODE can be produced from linoleic acid by 12/15-lipoxygenase that is induced in macrophages by interleukin (IL)-4, inhibiting the transcriptional activity of nuclear factor of activated T cells (NFAT) and nuclear factor- $\kappa \mathrm{B}(\mathrm{NF}-\kappa \mathrm{B})$ in phorbol myristate acetateactivated peripheral blood $\mathrm{T}$ cells, resulting in the suppression of IL-2 production. ${ }^{29,30)}$ Given that 9-HODE can be produced in monocytes or lymphocytes ${ }^{26}$ ) leading to activation of PPAR $\gamma$ that is more potent than 13-HODE activation, ${ }^{18)} 9$ HODE is expected to exhibit anti-inflammatory or immunomodulating activity more efficiently than 13 -HODE. Therefore, 9-E,E-HODE (2), as a potent PPAR $\gamma$ agonist, may also serve as an inflammatory modulator like 9-HODE. Presently, the synthetic PPAR $\gamma$ agonists thiazolidinediones are widely used as insulin sensitizers, and other anti-inflammatory drugs that can activate PPAR $\gamma$ are used in the treatment of inflammatory bowel diseases. ${ }^{31)}$ In addition to the present PPAR $\gamma$ agonists, 9-E,E-HODE (2) may also be a potential therapeutic agent for insulin resistance, diabetes, and bowel diseases. Moreover, the adlay seed has been reported to exhibit anti-inflammatory, anti-obesity, anti-hyperlipidemia, and anti-allergic effects, some of which may be explained by the effects of 9-E,E-HODE (2) and other hydroxy unsaturated fatty acids. To date, some PPAR $\gamma$ agonists have been isolated from plants and their active compounds included coumarin, ${ }^{32}$ 
prenylflavonoids, ${ }^{33)}$ and triterpenoids, ${ }^{34-36)}$ the structures of which are much different from those of hydroxy unsaturated fatty acids. Although only a few PPAR $\gamma$ agonists have been isolated for the first time from adlay seeds in the present study, additional PPAR $\gamma$ agonists with other distinct structures need to be determined to further understand the complexity of PPAR $\gamma$ regulation and development of potential PPAR $\gamma$ agonists.

In summary, 6 hydroxy unsaturated fatty acids were isolated and their structures determined. Among them, 9-E,EHODE (2), a geometrical isomer of 9-HODE, exhibited $\operatorname{PPAR} \gamma$ agonist activity as potent as 9-HODE. The finding that 9-E,E-HODE (2), which seems to possess characteristics distinct from 9-HODE, exists in adlay seeds may support the clinical usage of adlay seeds as a therapeutic agent for inflammatory diseases, diabetes, or insulin resistance and the development of novel PPAR $\gamma$ agonists without a number of deleterious effects such as peripheral edema, fluid retention and significant weight gain, shown by thiazolidinediones. ${ }^{6}$ Future studies need to focus on the biosynthetic pathway of 9-E,E-HODE (2) in adlay seeds.

Acknowledgements This work was supported by a Grant-in-Aid for Scientific Research from the Ministry of Education, Culture, Sports, Science and Technology of Japan (19590704).

\section{REFERENCES}

1) Tontonoz P., Hu E., Spiegelman B. M., Cell, 79, 1147-1156 (1994).

2) Tontonoz P., Hu E., Graves R. A., Budavari A. I., Siegelman B. M., Genes Dev., 8, 1224-1234 (1994).

3) Heikkinen S., Auwerx J., Argmann C. A., Biochim. Biophys. Acta, 1771, 999-1013 (2007).

4) Tontonoz P., Spiegelman B. M., Annu. Rev. Biochem., 77, 289-312 (2008).

5) Pascual G., Fong A. L., Ogawa S., Gamliel A,. Li A. C., Perissi V., Rose D. W., Willson T., Rosenfeld M. G., Glass C. K., Nature (London), 437, 759-763 (2005).

6) Rubenstrunk A., Hanf R., Hum D. W., Fruchart J. C., Staels B., Biochim. Biophys. Acta, 1771, 1065-1081 (2007).

7) Buckingham R. E., Hanna A., Diabetes Obes. Metab., 1, 312-328 (2008).

8) Hung W. C., Chang H. C., J. Agric. Food Chem., 51, 7333-7337 (2003).

9) Seo W. G., Pae H. O., Chai K. Y., Yun Y. G., Kwon T. H., Chung H. T., Immunopharmacol. Immunotoxicol., 22, 545-554 (2000).

10) Kim S. O., Yun S. J., Lee E. H., Am. J. Clin. Med., 35, 297-308 (2007).

11) Kim S. O., Yun S. J., Jung B., Lee E. H., Hahm D.H., Shim I, Lee H.
J., Life Sci., 75, $1391-1404$ (2004).

12) Ukita T., Tanimura A., Chem. Pharm. Bull., 9, $43-46$ (1961).

13) Tanimura A., Chem. Pharm. Bull., 9, 47-53 (1961).

14) Takahashi M., Konno C., Hikino H., Planta Med., 52, $64-65$ (1986)

15) Otsuka H., Hirai Y., Nagao T., Yamasaki K., J. Nat. Prod., 51, 74-79 (1988).

16) Itoh T., Fairall L., Amin K., Inaba Y., Szanto A., Balint B. L., Nagy L., Yamamoto K., Schwabe J. W. R., Nat. Struct. Mol. Biol., 15, 924-931 (2008).

17) Krey G., Braissant O., L'Horset F., Kalkhoven E., Perroud M., Parker M. G., Wahli W., Mol. Endocrinol., 11, 779-791 (1997).

18) Nagy L., Tontonoz P., Alvarez J. G. A., Chen H., Evans R. M., Cell, 93, 229-240 (1998).

19) Delerive P., Furman C., Teissier E., Fruchart J., Duriez P., Staels B., FEBS Lett., 471, 34-38 (2000).

20) Christina B. J., Benny J., Kim M., Joergen M., J. Am. Oil Chem. Soc., 74, 277-284 (1997).

21) Muuse B. G., Cuperus F. P., Derksen J. T. P., J. Am. Oil Chem. Soc., 71, 313-317 (1994)

22) Koshino H., Togiya S., Yoshihara T., Sakamura S., Shimanuki T., Sato T., Tajimi A., Tetrahedron Lett., 28, 73-76 (1987).

23) Altmann R., Hausmann M., Spöttl T., Gruber M., Bull A. W., Menzel K., Vogl D., Herfarth H., Schölmerich J., Falk W., Rogler G., Biochem. Pharmacol., 74, 612-622 (2007).

24) Hampel J. K. A., Brownrigg L. M., Vignarajah D., Croft K. D., Dharmarajan A. M., Bentel J. M., Puddey I. B., Yeap B. B., Prostaglandins Leukot. Essent. Fatty Acids, 74, 283-293 (2006).

25) Daret D., Blin P., Dorian B., Rigaud M., Larrue J., J. Lipid Res., 34, 1473-1482 (1993)

26) Engels F., Kessels G. C. R., Henricks P. A. J., Nijkamp F. P., Prostaglandins, 52, 117-124 (1996).

27) Bensinger S. J., Tontonoz P., Nature (London), 454, 470-477 (2008).

28) Wigren J., Surapureddi S., Olsson A. G., Glass C. K., Hammarström S., Söderström M., J. Endoclinol., 177, 207-214 (2003).

29) Yang X. Y., Wang L. H., Mihalic K., Xiao W., Chen T., Li P., Wahl L. M., Farrar W. L., J. Biol. Chem., 277, 3973-3978 (2002).

30) Huang J. T., Welch J. S., Ricote M., Binder C. J., Willson T. M., Kelly C., Witztum J. L., Funk C. D., Conrad D., Glass C. K., Nature (London), 400, 378-382 (1999).

31) Rousseaux C., Lefebvre B., Dubuquoy L., Lefebvre P., Romano O., Auwerx J., Metzger D., Wahli W., Desvergne B., Naccari G. C., Chavatte P., Farce A., Bulois P., Cortot A., Colombel J. F., Desreumaux P., J. Exp. Med., 201, 1205-1215 (2005).

32) Kuroyanagi K., Kang M. S., Goto T., Hirai S., Ohyama K., Kusudo T., Yu R., Yano M., Sasaki T., Takahshi N., Kawada T., Biochem. Biophys. Res. Commun., 366, 219-225 (2008).

33) Mae T., Kishida H., Nishiyama T., Tsukagawa M., Konishi E., Kuroda M., Mimaki Y., Sashida Y., Takahashi K., Kawada T., Nakagawa K., Kitahara M., J. Nutr., 133, 3369-3377 (2003).

34) Han K. L., Jung M. H., Sohn J. H., Hwang J. K., Biol. Pharm. Bull., 29, 110-113 (2006).

35) Sato M., Tai T., Nunoura Y., Yajima Y., Kawashima S., Tanaka K., Biol. Pharm. Bull., 25, 81-86 (2002).

36) Takahashi N., Kawada T., Goto T., Kim C. S., Taimatsu A., Egawa K., Yamamoto T., Jisaka M., Nishimura K., Yokota K., Yu R., Fushiki T., FEBS Lett., 550, 190-194 (2003). 